\title{
DOSSIE
}

\section{Cartografia de uma história: exercícios cartomuseográficos e releituras cosmográficas - séculos XVI e XVII}

\author{
Introdução
}

\author{
Beatriz P. Siqueira Bueno ${ }^{1}$ \\ Íris Kantor ${ }^{2}$ \\ Vera Lúcia A. Ferlini ${ }^{3}$
}

O dossiê que ora apresentamos não é mera tradução de Cartografia de uma história - São Paulo colonial: mapas e relatos, exposição realizada no Museu Paulista da Universidade de São Paulo, entre 11 de março de 2005 e 11 de junho de 2006, sob coordenação da Cátedra Jaime Cortesão-USP. É também seu desdobramento. A interação com pesquisadores de diferentes áreas e instituições, ao longo da concepção e montagem da exposição, motivou o convite para elaborarem ensaios relacionados aos vários temas propostos pela curadoria, de modo a ampliar os debates e reflexões então suscitados. Desse esforço, resultaram dois dossiês para publicação nos Anais do Museu Paulista, neste número e no próximo.

Este primeiro dossiê trata da concepção curatorial e da cartografia quinhentista e seiscentista, contemporânea da expansão marítima européia; o segundo, vai focalizar a cartografia setecentista e o processo de formação territorial do Brasil. Ambos têm em comum uma perspectiva teórico-metodológica que entende a cartografia como fonte material para estudos históricos, evitando-se seu recorrente uso ilustrativo. Tomados como evidência material para a história social e cultural, os documentos cartográficos também apresentam enorme potencial para
1. Docente da Faculdade de Arquitetura e Urbanismo da USP, curadora-científica da exposição Cartografia de uma bistória - São Paulo colonial: mapas e relatos. E-mail: <beatrizbueno@terra. com.br>.

2. Docente do Departamento de História da FFLCH-USP, curadora-científica da exposição Cartografia de uma bistória - São Paulo colonial: mapas e relatos. E-mail: <ikantor@usp.br>.

3. Docente do Departamento de História da FFLCH-USP, coordenadora-geral da exposição Cartografia de uma bistória - São Paulo colonial: mapas e relatos. E-mail: $<$ veferlin@usp.br>. 
4. Professores, pesquisadores e estagiários do Museu Paulista, do Departamento de História da FFLCH e da Faculdade de Arquitetura e Urbanismo da Universidade de São Paulo. os estudos geopolíticos e fundiários, que extrapolam seus atributos de raridade estética ou mercantil, tão banalizados no mundo contemporâneo.

O primeiro Dossiê, publicado neste número, foi dividido em duas partes: a primeira, dedicada aos exercícios cartomuseográficos realizados durante a montagem da referida exposição; a segunda, orientada às diferentes leituras da cosmologia e cosmografia do Renascimento. A primeira parte, denominada Experimentações cartomuseográficas, apresenta três ensaios sobre o processo de concepção interdisciplinar e interdepartamental ${ }^{4}$ da exposição no Museu Paulista - na atualidade, um dos principais centros de pesquisa dedicados aos estudos de cultura material. Estas experimentações foram motivadas pelo desafio de enfrentar esse "lugar de memória" (na expressão consagrada de Pierre Nora), arquitetado por Affonso d'Escragnolle Taunay (seu terceiro diretor), para evocar a épica bandeirista.

Uma das primeiras iniciativas de Taunay quando assumiu a direção do Museu Paulista, em 1917, foi iniciar a coleta de documentos visuais e referências textuais que pudessem celebrar o passado sertanista. A concepção da sala Cartografia colonial e documentos antigos (Figura 1), vinculou-se diretamente com esse intento. Ali foi exposta a monumental Carta Geral das Bandeiras Paulistas, executada sob sua orientação e desenhada por Gregório Colás e José Domingues Santos Filho, cartógrafos do Museu Paulista, em escala de 1:5.500.000, em 1921. Figurando com grande destaque no centro da principal parede da sala, a Carta procurava ilustrar didaticamente a importância dos bandeirantes paulistas na construção do território nacional. Na sala, a Carta Geral esteve circundada pelos retratos de grandes vultos da pátria: Rio Branco, Alexandre de Gusmão (evocados por sua relação com a definição de fronteiras), D. Pedro I, José Bonifácio, Domingos Jorge Velho, etc. Não seria um exagero dizer que a cartografia foi um recurso muito importante na "cenarização museológica" proposta por Taunay, como fica patente no seu empenho em mandar copiar os mapas brasileiros nos principais arquivos estrangeiros e nacionais.

Romper com esse viés interpretativo, materializado pelo acervo permanente e pelos espaços internos pré-definidos, obrigou-nos a buscar novos recursos tecnológicos e museográficos para, simultaneamente, desconstruir e reconstruir uma outra lógica de associações entre os objetos do acervo e a documentação cartográfica que tínhamos em mãos. Procurando escapar da perspectiva cartográfica tradicional de uma exposição linear de mapas, instrumentos e livros, recorremos aos novos suportes audiovisuais disponibilizados por tecnologias contemporâneas de georreferenciamento, composição musical e animação em 3D.

O artigo de Ricardo Bogus - responsável pela concepção museográfica - expõe a estrutura e as peculiaridades deste projeto expositivo. As fotos publicadas revelam os artifícios lúdicos mobilizados na ambientação das diversas salas, com o intuito de captar a atenção dos visitantes, instigando o ato de descobrir. Já Anna Maria Kieffer apresenta o roteiro sonoro elaborado para a sala dedicada à cartografia dos sertanistas e às experiências de devassamento dos sertões da capitania de São Paulo. As representações gráficas e discursivas foram convertidas 


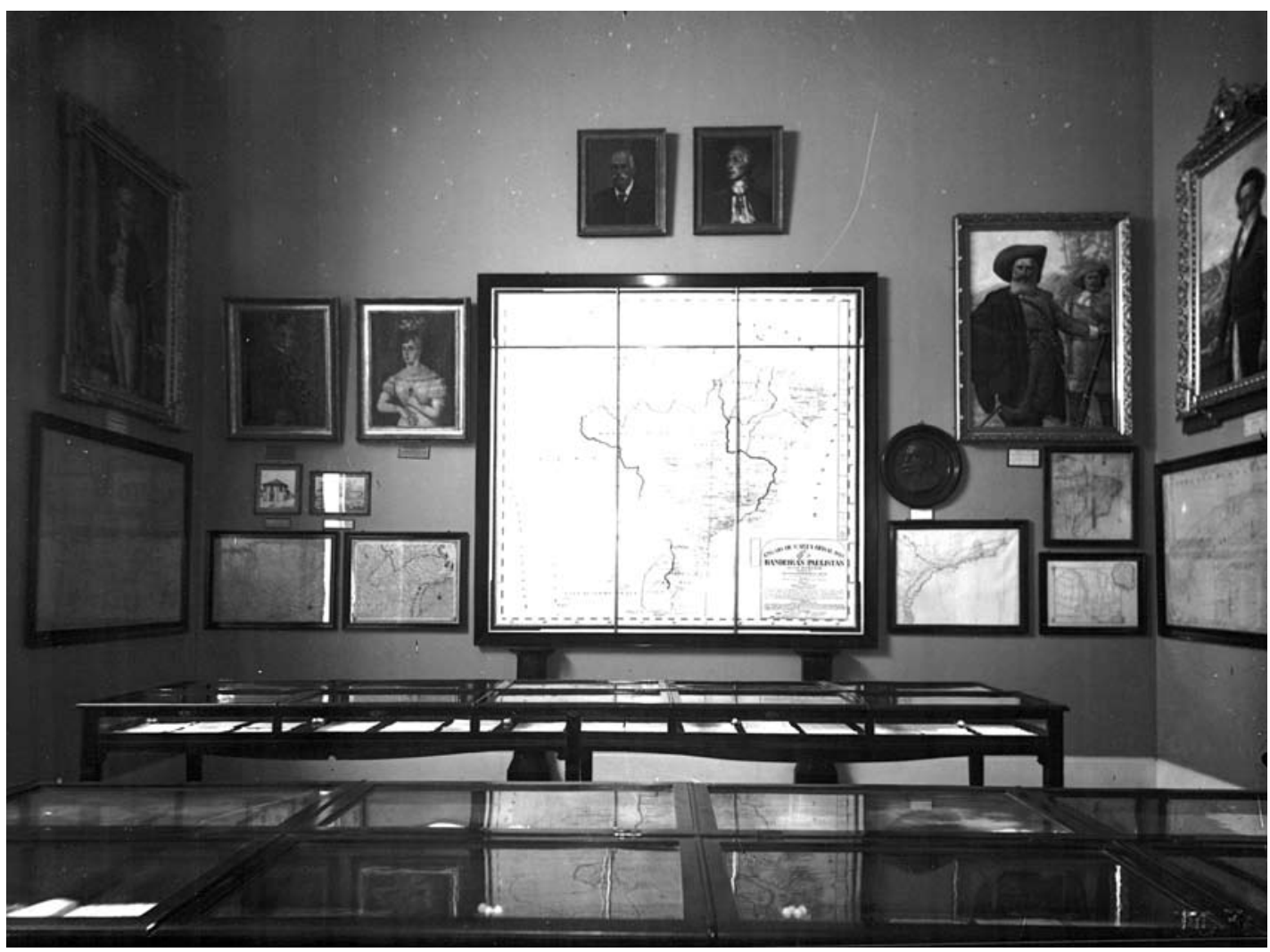

Figura 1 - Anônimo. Sala de Cartografia colonial e documentos antigos, c. 1937. Fonte: TAUNAY, Affonso d’Escragnolle. Guia da Secção Histórica do Museu Paulista. São Paulo: Imprensa Oficial do Estado, 1937, p. $72 \mathrm{C}$.

em cartografia musical pela musicista e pesquisadora, que soube explorar a sonoridade como suporte, recriando com rara sensibilidade uma cartografia inédita das vivências no sertão. Inspirada nas leituras de diários, testamentos, atas das câmaras, documentos etnográficos e mapas rústicos feitos nos caminhos, nas trilhas e rios, a trilha sonora pôs em destaque os aspectos intangíveis das percepções de tempo e espaço: durações das viagens, os sabores da culinária bugre, as rezas e as ladainhas de proteção dos sertanistas.

No artigo de Paulo Martini, Joaquim Godoy, Ricardo Arduino, Sílvio Coimbra e Guilherme Silva, o leitor terá oportunidade de acompanhar os resultados da parceria com a equipe do Instituto Nacional de Pesquisas Espaciais (Inpe), que permitiu o georreferenciamento das redes - urbanas e de caminhos - e seus fluxos, transpondo, para imagens de satélite, informações de mapas antigos. Tais exercícios nos dão a real dimensão virtual inscrita no impulso cartográfico, que plasmou o território ao dar-the tangibilidade. As tecnologias de última geração facultam não só esse diálogo mas também a aproximação de tempos distintos, permitindo revisitar antigos debates historiográficos sobre a configuração geofísica

Annals of Museu Paulista. v. 17. n.1. Jan. - June 2009. 
e geopolítica do território brasileiro, bem como assinalar as redes de caminhos e cidades desenhadas ao longo dos três primeiros séculos da colonização, acompanhando as mutações das fronteiras políticas da Capitania de São Paulo.

A segunda unidade deste dossiê - Leituras da cosmologia e cosmografia do Renascimento -, com perfil mais investigativo do que experimental, apresenta um conjunto de cinco estudos, aprofundando as possibilidades de leitura dos mapas. Partindo do pressuposto epistemológico de que mapas são representações visuais e culturais (e não, imagens miméticas da realidade espacial), esta unidade traz uma pequena amostra das potencialidades de abordagem da temática em questão. Com olhares variados para exemplares da era dos Descobrimentos, os autores interpretam as cosmologias e cosmografias que, desde a chegada dos europeus à América, transformaram completamente o modo de ver e representar o mundo.

Mundos em miniatura: aproximação a alguns aspectos da cartografia portuguesa do Brasil (séculos XVI a XVIII), de Joaquim Romero Magalhães, explora, numa perspectiva de conjunto, o lento processo de conhecimento e tradução visual resultante da expansão ultramarina e da colonização dos Novos Mundos conquistados por Portugal.

Por intermédio de um estudo de caso, o artigo A carta náutica de Piri Reis, 15 13, do Almirante Max Justo Guedes, descortina as práticas de apropriação de conhecimentos cartográficos presentes no famoso mapa do Almirante otomano Piri Reis, que se valeu da experiência portuguesa para compor a sua carta náutica.

ensaio Volta ao mundo por ouvir-dizer: redes de informação e a cultura geográfica do Renascimento, de Plínio Freire Gomes, problematiza a dimensão estratégica da circulação das informações geográficas na época da expansão ultramarina. Mostra como os segredos cartográficos registrados nas cartas-padrão ibéricas, monopolizadas pelas casas de contratação, estiveram sujeitos a um contínuo processo de corrosão. De maneira curiosa, versa sobre a contraditória necessidade das Coroas ibéricas de ratificar a posse dos novos territórios coloniais através da publicidade, o que contrariava a política do sigilo, então vigente.

No mesmo diapasão, Dante Martins Teixeira - em seu Todas as criaturas do mundo: a arte dos mapas como elemento de orientação geográfica-empreende uma densa interpretação iconológica dos mapas medievais e renascentistas, mostrando o papel e o significado das figurações no reconhecimento de terras desconhecidas pela cristandade européia. Num mundo em que latitudes e longitudes eram pouco precisas ou confiáveis, os acidentes da paisagem, os povos existentes e até mesmo determinados componentes da fauna e flora foram variáveis de extrema importância para a orientação geográfica, extrapolando sua dimensão de meros adereços decorativos.

Por fim, o artigo de Ana Paula Torres Megiani - Memória e conhecimento do mundo: coleções de objetos, impressos e manuscritos nas livrarias de Portugal 
e Espanha, séculos XV-XVII - repisa a temática da circulação e consumo de mapas nas Câmaras de Maravilhas e Gabinetes de Curiosidades, assim como nos espaços da Corte filipina. Explora a especificidade do "colecionismo" no período, analisando as livrarias privadas de homens como Manoel Severim de Faria, em Portugal, e Jerônimo de Mascarenhas, na Espanha, ambos contemporâneos da União lbérica.

Completa esse dossiê o audiovisual Desenhos do Mundo, executado por Paulo Pastorello e João de Abreu Sodré, que o leitor poderá acessar virtualmente no site da coleção SciELO Brasil. Concebido para uma das salas da exposição supracitada, entre as modernas tecnologias empregadas na mostra, o audiovisual pretendeu desnaturalizar as representações e percepções morfográficas dos oceanos e continentes, convencionalmente cristalizadas em nosso imaginário. Nessa empreitada, contamos mais uma vez com a sensibilidade do compositor eletroacústico belga Leo Kupper, que compôs a trilha sonora. No mesmo site, também será possível ouvir a trilha sonora de Anna Maria Kieffer, idealizada para sala dos sertanistas.

Nesta longa trajetória, da exposição ao dossiê que ora apresentamos, contamos com as gentis colaborações de diversos pesquisadores e profissionais, aos quais agradecemos imensamente o apoio: o Almirante Max Justo Guedes, Rosemarie Érika Horch (in memoriam), o professor Joaquim Romero de Magalhães, João Carlos Garcia, Maria Marlene de Souza (Ministério das Relações Exteriores), Dulce Maria Faria (Biblioteca Nacional) e a equipe de Miguel Pacheco Chaves, especializada no tratamento de imagens digitais e impressão em alta resolução. Nada disso teria sido possível sem o entusiasmo e ímpeto realizador de Eni Mesquita Samara, diretora do Museu Paulista na ocasião da exposição. 